\title{
Performance Contract and Performance of Public Enterprises: A Study of the Implementation Processes
}

\author{
Samuel Nana Yaw Simpson ${ }^{1}$ \\ Department of Accounting, University of Ghana Business School \\ P. O. Box LG 78, Legon, Accra.
}

Dr. Thomas Buabeng

Department of Public Administration \& Health Services

University of Ghana Business School, P. O. Box LG 78

Legon, Accra.

Received: May 08, 2013 Accepted: May 22, 2013 DOI: 10.5296/jpag.v3i2.3792

\begin{abstract}
This paper primarily seeks to identify and analyse the factors that explain mixed evidence in relation to the impact of performance contract on the performance of public enterprise. To achieve this primary objective, the study adopted multiple case study strategy. Specifically, four public enterprises representing four cases were randomly sampled based on the performance assessment categorisation; excellent (A), above average (B), average (C), and fair (D), by the State Enterprises Commission (SEC). The findings of the study show that the content, targets, and objectives in the performance contracts are always specific, clear and measurable. There are variations in how each of the four cases formulate performance targets and objectives in their contracts. SOEs in categories A and B have separate department exclusively in charge of corporate planning. Furthermore, these SOEs have clearly designed structures and systems for formulating and implementation the contents of PC. In fact, SOEs in categories A and B were found to combine both top-down and bottom up approaches in their PC processes. Although the findings show that all SOEs face similar political inferences, financial and human resources have been identified from the study as vital in contributing to the performance of SOEs in formulating and implementing the contents of performance contract.
\end{abstract}

On the basis of the above findings, this paper recommends among other things, the need to go beyond SEC and focus on the institutional arrangements for formulating and implementing the content of performance contract within SOEs. Furthermore, the approach adopted by SOE A; trainees becoming trainers must be extended to other SOEs to build competent and qualified human resource base for the SOE sector.

\footnotetext{
${ }^{1}$ Corresponding email: snysamuel@ug.edu.gh

The authors are grateful to the Research and Conference Committee, UGBS for the partial financial support
} 


\section{Introduction}

Over the past three decades, the public sectors of developed and developing countries have experienced a phenomenal rate of reform experimentations with varying objectives and degree of emphasis. The reform programmes broadly cover policies, structures, and practices to make the public sector more business-like, enhance efficiency, effectiveness, transparency and accountability, and ultimately strengthen and improve the management and performance of the entire public sector (Hood, 1995; Lapsley, 2008; Omoyefa, 2008; Page, 2005; Schacter, 2000). These range of reforms which have been categorized by some authors as New Public Management (NPM) may assume one of six core approaches namely Downsizing, Debureaucratization, Privatization, Decentralization, Performance evaluation, and New Managerialism also referred to as Performance Contract (PC).

Many developing countries including Ghana have experimented, in various degrees, almost all six approaches. However, existing studies show that much attention has been focused on the privatization and decentralization approaches than the others (Ariyo and Jerome, 1999; Yonnedi, 2010; World Bank, 1983, 1995). These have resonated calls for studies on the other reform strategies (Basu, 2007; Chang, 2007, Uddin and Tsamenyi, 2005; World Bank, 1995), particularly the non-divestiture reform programmes (Chang, 2007).

Performance contract (PC) is a key non-divestiture reform to, among other things, ensure improved performance in the entire public sector (including SOEs). It seeks to achieve this by encouraging accountability, managerial autonomy, corporate planning, information flow, monitoring, and formalization of State Owned Enterprises (SOEs) (Islam, 1993; Nellis, 1989; Shirley, 1989, 1996; Trivedi, 1990).

However, there have been limited empirical studies on implications of performance contracts (Mallon, 1994; Shirley and Xu, 1998; Simpson and Onumah, 2010; World Bank, 1995). With regards to the impact of performance contract on the performance of SOEs, evidence reported in the literature are mostly mixed (Larbi, 2001; Shirley and Xu, 2001; Simpson and Onumah, 2010; World Bank, 1995). Moreover, explanations for the mixed evidence are problems associated with the relationship between government and mangers of public enterprises (political interference); the PC process; institutional challenges, and other anecdotal evidence.

This paper therefore seeks to identify and analyse the factors that may explain the reported mixed results. Unlike the existing studies, the current study is draws from well-established public policy implementation models to provide more comprehensive empirical evidence. Indeed, policy implementation models take cognizance of all the processes of carrying out and translating policies into practice; and actions by public and private individuals. Furthermore, the models posits that the success or failure of any public policy depends on policy standards and objectives, policy resources, inter organizational communication and enforcement activities, characteristics of implementing agencies, economic social and political conditions, and the disposition of implementers. A study of this nature extends the application of the public policy implementation models to performance contracts, and contributes empirically to the literature on performance management in the context of a developing country. 


\section{Overview of the Literature on Performance contract and implementation Models}

Performance contracts have variously been defined and described as contract-plan, memorandum of understanding, signalling system, performance agreement, results framework, incentive contracts, performance monitoring and evaluation system, and many more. Nellis (1989) ${ }^{2}$ defines PC as a negotiated agreement between government as the owner of public enterprises and the management of enterprises, outlining the underlying principles, rights, obligations and responsibilities of both parties. Other scholars add that the agreement may be formalised by clearly defining objectives, specifying targets, intentions, obligations, responsibilities, and pledges made by parties concerned, as well as the managerial autonomy required to achieve the expected goals within a given time frame (Caulfield, 2006; Islam, 1993; Shirley and Xu, 1997, 1998, Shirley, 2000).

From the reform literature, performance contract has multiple objectives including restructuring, ensuring managerial autonomy, accountability, performance monitoring and evaluation (see e.g. Islam, 1993; Larbi, 2001; Mallon, 1994; OECD, 1999; Trivedi, 1990; UN, 1995) and in recent years they have become a performance management strategy in the public sector (Cualfield, 2006). Moreover, there are several models of performance contract across the globe. Shirley and Xu (1998) cite the three-year contract targets (Senegal's contract plan); annual targets contract (Ghana's PC, India's memorandum of understanding, Korea's performance evaluation and monitoring systems, and Philippines' performance monitoring and evaluation system); and Pakistan's signalling system.

Despite the many models, the underlying theories and principles are generally the same. For instance, performance evaluation and corporate planning form an integral part of the system to ensure improved performance. Furthermore, all the models have standardized content covering areas such as vision and mission, obligations of parties to the contract, incentives, and performance monitoring and evaluation targets (Islam, 1993, Nellis, 1989; Shirley, 2000). However, there are some variations with respect to pre-contract and post-contract periods and activities, scope and institutional procedures. Indeed, these variations have the potential of affecting the success or failure of the entire performance contract system, hence the need to identify and analyse the factors associated with the implementation of performance contract.

The literature presents a numbers of implementation models. Van meter and Van Horn (1975) posit an implementation model aims at directing the attention of those who study implementation rather than providing prescription. This makes it ideal for use in this study since it could provide the needed guide in studies of all kinds of context. The model suggests that there is the need to take into account the amount of change required and the level of consensus. They accordingly hypothesized that: 'implementation will be most successful where only marginal change is required and goal consensus is high because the struggles which minor change with high consensus policies cause are less severe.' They further explain that such policies reflect in the nature of instrumentalism, a political routine that stipulates that current policy decisions are largely a function of previous decisions. Incremental decisions by definition discourage controversy by deviating only marginally

\footnotetext{
${ }^{2}$ Nellis is one of the foremost authors on PC as a World Bank intervention in developing countries
} 
from previously accommodations and practices. Moreover, the probability of effective implementation will depend, in part, on the type of policy being considered and that the specific factors contributing to the realization or non-realization of program objectives will vary from one policy type to another.

Elements of the foregoing implementation model are tagged, top-down model. Van Meter and Van Horn (1975) explain that the model demands that "the study of implementation is conducted longitudinally; relationships identified at one point in time must not be extended causally to other time periods" ( $p, 447)$. The model suggests six variables linked dynamically to the production of an outcome. These include policy standards and objectives, policy resources, inter organizational communication and enforcement activities, characteristics of implementing agencies, economic social and political conditions, and the disposition of implementers. The authors add that it is above core variables that shape the linkage between public sector reform and its implementation. They explained that policy standards and objectives elaborate on the overall goals of a policy decision and that "they move beyond the generalities of the legislative document to provide concrete and more specific standards for assessing programme performance (ibid)."

Another notable element is the availability of resources to facilitate the administration of policy standards and objective. Resources may include funds or other incentives in the programme that might encourage or facilitate effective implementation. Inter organizational communication and enforcement activities have also been identified as affecting effective implementation of a policy. The model further explains that, several factors within the environment may directly or indirectly influence the implementation process. They include availability of resources, impact of the economic, social and political conditions prevailing at the time and the nature of public opinion existing in the environment within which the implementation is being carried out. The dispositions of implementers' as well as the characteristics of the implementing agencies have also been identified as affecting successful implementation of public sector reforms.

Grindle and Thomas (1991) developed another model known as "the interactive model". It focuses on the conflict and reactions that are often evoked by efforts to bring about policy reforms for development and the resources policy makers and managers require in sustaining the reform in the face of such reactions. This model was developed as an alternative to what they described as the "linear model of policy implementation." They argue that the linear model assumes that a proposed reform gets on the agenda for government action, a decision is made on the proposal and the new policy or institutional arrangement is implemented. In this context, if implementation is unsuccessful, the usual remedy is to call for greater effort to strengthen institutional capacity or blame failure on lack of political will (Grindle and Thomas 1991).

However, Grindle and Thomas argue that the role of implementation in the policy process is substantially different from what is presented by the linear model. To them, implementation is often the most crucial phase of the policy process. The model assumes that a state of equilibrium surrounds an established policy set. This equilibrium results from the acceptance of existing policy by those who are affected - positively or negatively - by them. Any effort 
at altering the existing policy upsets that equilibrium and will elicit some reaction from those affected by the change. The interactive model views policy reform as a process, one in which interested parties can exert pressure for change at many points. The central element in the model, they argue, is that a policy reform initiative may be altered or reversed at any stage in its life cycle by the pressures and reactions of those who oppose it. Understanding the location, strength, and stakes involved in these attempts to promote, alter, or reverse policy reform initiatives is therefore central to understanding the outcomes.

The interactive model concludes that, the outcome of reforms is largely determined by how bureaucratic agencies, administrative routines and public officials interact in responding to the reforms. At this stage, it is argued, the reform is particularly vulnerable, because mobilizing political, financial, managerial and technical resources becomes challenging due to the fact that those opposing the policy may attempt to block access to the necessary resources thereby stalling the entire programme.

Another important implementation model is one by Bo Rothstein (Rothstein, 1998). It emphasises on three core factors namely policy design, organization of the implementation process, and political legitimacy. Rothstein's model differs from the above models in two perspectives. First is his argument that all three variables must be available before implementation of reforms could succeed. Second, is his focus on the centrality of the appropriate implementing institution and political legitimacy and trust. He emphasizes that, the "different ways of organizing public administration affect the prospects for carrying out programmes successfully" (Rothstein, 1998:7). He opines that the best way of organizing policy implementation depends on the type of task the implementing organization must carry out. To him without beneficiaries' trust in the implementing institutions, implementation is likely to fail because no public sector reform can be implemented successfully without wining legitimacy of those who are to be affected (Rothstein, 1998:100).

\section{Methodology}

To realize the foregoing research objective, the study employed the qualitative approach of social research. This involves an investigation that attempts to "provide generic prepositional answers to questions about social life and organizations....... strives to present data and analysis that are true; seeks to provide data and/or analysis that are new; and present an analysis that is developed in the senses of being conceptually elaborated, descriptively detailed, and concept-data interpenetrated" (Lofland 1996: 30). In other words, this paradigm is most appropriate in providing more comprehensive understanding of the meaning, context and challenges of implementing any public policy including performance contract.

Furthermore, the case study approach was used in the study. As an empirical enquiry to investigate contemporary phenomenon in real life context, the case study strategy provides a more holistic approach to understanding any phenomenon (Yin, 2003), hence the pro- public enterprise performance policy implementation in Ghana. Moreover, the availability of multiple sources of information that are interactive and humanistic makes the case study strategy appropriate for this study.

In all, four public enterprises representing four cases were covered in this study. The selection 
of cases was based on performance per the assessment of State Enterprises Commission (SEC). SEC is the oversight body in charge of the performance monitoring and evaluation of SOEs in Ghana under the performance contract. Specifically, the four cases were randomly sampled based on SEC assessments under the categories: excellent, above average, average, and fair. For the purposes of simplicity and clarity, this paper has re-labelled the categories as A for excellent, $\mathrm{B}$ for above average, $\mathrm{C}$ for average, and $\mathrm{D}$ for fair.

The data for the study were obtained from both primary and secondary sources. The primary source consisted mainly of data collected from the study areas through in depth interviews between $2^{\text {nd }}$ February and $10^{\text {th }}$ March 2013. Bearing in mind the objectives of the study as well as the nature of the cases studied, the in-depth interviews method was used. In all, 15 respondents were interviewed. The participants comprised of 3 each from the four selected Public Enterprises. In addition, a participant each was interviewed from the State Enterprises Commission (SEC), Ministry of Finance and Economic Planning (MOFEP) and the Sector or parent Ministries. All the participants were among the senior management officials involved in the implementation process of the performance contract in each of the organizations studied.

Voice recorders were used to record the information from the respondents (where possible), and backed-up by taking detailed notes to ensure that in the event that the recording equipment fails the data would not be lost. The data from the field were then organized for analysis. Here all recorded interviews were transcribed and coded using the constant comparative method of data analysis and all handwritten notes typed (Silverman, 2004).

\section{Data analysis and discussion}

The section below presents the analysis and discussions of the data collected from the field of study. It has been organized under four major themes to coincide with the objectives of the study. These are policy standards and objectives, institutional arrangements, resources, and politics. Each of the four themes consists of a comparative analysis of the four categories of SOEs described earlier. In other words, the analysis and discussion compares the implementation performance of PC among the four categories of SOEs in Ghana under the four main headings.

\subsection{Formulation of Objectives and Targets in Performance contract}

According to Meter and Horn (1975), policy standards and objectives may be one of the core variables that shape the linkage between public policy and its implementation and for that matter success or failure in public policy implementation. According to the pair, all public policies have policy standards and objectives that elaborate on the overall goals. The policy standards and objectives "move beyond the generalities of the legislative document to provide concrete and more specific standards for assessing programme performance (Meter and Horn 1975; 447)."

In this paper the authors focused on policy standards and objectives to find out whether the organizations have clear understanding of the PC and the performance targets therein; whether they are specific, measurable and attainable. All the cases indicated that the content, targets, and objectives in the performance contracts are always specific, clear and measurable. 
In fact, the targets for all the four cases are grouped under four main themes; financial/economic, efficiency/productivity, dynamic effects, and management improvement/projects. But for purposes of performance evaluation, these performance targets are re-classified into three theme; economic/financial, dynamic effects, and management improvement/projects. The first theme measures targets like profitability, output, productivity and efficiency, but mainly depends on whether the SOE is a profit oriented or not. The dynamic effect is more about the staff training, corporate planning, and programmes undertaken by SOEs on staff health and safety as well as maintenance of equipment, etc. The last is the management improvement targets which cover targets such as preparing and submitting timely audited financial statements, draft performance contract, budgets, procurement planes, board minutes, and so on.

There are however, clear variations in how each of the case formulate performance targets and objectives in the contracts. In SOE A the targets vary significantly on yearly basis compared to those in categories B, C and D which appears the same with incremental modification to the previous standards and objectives. Moreover from the interviews, officials of SOEs in category A and partly B attach so much importance to the formulation of performance targets and objectives. For instance, both SOEs have a department exclusively in charge of gathering information from operations and departments for corporate planning and formulation of performance targets and objectives. In the specific case of SOE A, targets from each department emanate from the staff in each department and not just the head of department.

\subsection{Institutional Arrangements}

It has been argued by various studies in policy implementation in developing countries that institutional arrangements frustrates the realization of the goals and objects as set out in public policies and programmes (Buabeng 2010, Maliha, Buabeng and Ahenkan 2013). The institutional arrangements for the implementation of PC are very important in understanding the differences in the levels of effectiveness of the implementation. This, we also refer to as the implementation structure is defined to mean the official arrangement of actors, institutions, organizations and processes employed in the implementation process of PC. Rothstein (1998) explains that “....using an inappropriate organizational structure often leads to failure in the stage of implementation - forms of organization are like tools - they are only suitable for the performance of certain definite tasks" (p, 89). In the opinion of Mazmanian and Sabatier $(1983 ; 27)$, the degree of hierarchical arrangement of the implementing agency can have significant influence on the timeliness in carrying out the policy. They emphasized that "to the extent that the system is only loosely integrated, there will be considerable variation in the degree of behavioural compliance among implementing officials and target groups and individuals as each responds to the incentives for modification within their local setting" (ibid).

The above implies that implementation structures in the studied SOEs would vary significantly in terms of structures and institutions established for the implementation of PC. The study found that SOEs in groups A and B tend to combine both top-down and bottom up approaches in their PC processes. For instance the two categories rely on their divisions and 
lower level units to generate data to formulate objectives and targets, but the implementation tend to be more top-down with extensive supervision, monitoring and controlling activities to ensure the realization of the objectives in the case of SOE A. However, the experience of the SOEs in categories C and D was different. Here, the SOEs have limited, if any, divisions and units to rely on in generating inputs for PCs. As a result, the approach tend to be top-down with the top management deciding on the content and process of PCs. When asked to explain why this approach a corporate planning officer of the category A organization studied remarked that:

Unlike the other SOEs where one person sit down to put all these things together and imposes it on the members to do it, here, what happens is that the various departments who have to implement the targets.................make inputs into the development of this project so that they feel they are part of the project. When the request for corporate plans come up, the department in charge also sends memo to all the other departments so when they make inputs they comply with everything and develop the corporate plan. Of course, the finance department is in charge of the budget, ...

One may argue from the above findings that, the nature of the institutional arrangements is likely to influence the commitment and motivation of employees towards the realization of the objectives of PC. This is because, there is a general belief that many policies require the consent, cooperation and support of those who are affected by it in order to be implemented effectively. This is partly because, research has shown that active participation in formulation of policies tend to lead to commitment and active participation in implementation thereby bringing about effectiveness in the process (Sachs 2003, Acemoglu 2003Rothstein 1998).

\subsection{Resources}

Another important variable that this paper argues can influence the effective implementation of PCs is the resources that the policy makes available to facilitate the administration of the implementation process. Implementation resources are defined in this paper to include funds and all other incentives that are provided in the PC document towards effective implementation. The availability or otherwise of resources is another factor which this paper opines that, it can influence the execution of PCs in Ghana. In other words, resources for the execution of PCs in Ghana include both financial and human resources as well as funds and other incentives meant to facilitate effective implementation of the contents of PCs. In the words of Hewlett \& Ramesh (2003), for effective policy implementation, "funding must be allocated, personnel assigned, and rules and procedures developed" (Hewlett \& Ramesh 2003; 185). It is an undeniable fact that like all developing countries, the Ghanaian public sector organizations has been historically, and continues to be characterized by inadequate financial and human resource. This is one of the major factors posing a great challenge to the implementation of PCs.

Interestingly, the study data shows that the sources of funding to SOEs in Ghana include Central Government transfers, funds generated by the SOEs from their own activities within the organization locally called, Internally Generated Fund (IGF), and external sources of funding which includes funding from loans (commercial and IMF/World Bank). In the case 
of each SOE in the study, different pictures about resources constrain emerges in their (SOEs) bid to effectively implements their respective PCs. The resources experiences range from adequate to very poor. The findings show that, the category B SOEs studied was the most resourced among all the organizations studied. This is largely because it generates enough financial resources and also has such a high credit rating that makes it very attractive to investors globally. Due to the strength in financial resources, the organization is able to attract quality and competitive human resource as well. This strength notwithstanding, the organization faces one major constrain. This is the frequent interference and pressure from government to borrow from it or interfere in the expenditure decisions of the organization to achieve political ends. It is therefore not surprising that this organization has consistently met its PC targets over the years. As observed by Rothstein (1998) "effective implementation has to do with the significance of resources and motivated and capable staff, and with the importance of continuously evaluating the implementing organization" (Rothstein 1998;89). Again, Rothstein is suggesting that effective implementation does not only require quality and skilled personnel but also a motivated and capable people. In other words, effective PC may be influenced by the competence and size of the implementing organization's staff which invariably influence the capacity of an organization to carry out public policies.

Category A is another category that has relatively better resources base, particularly in the area of human resources. One of the officials explained:

...historically, SOE B was generating financial resources from two main sources: internal and external (export) demands. So, revenue generated was used to train its human resource by sponsoring them to study in universities locally and those in developed countries. Moreover, staff were attached to organisations in similar areas of operation in developed countries to learn. Over time, local demand have exceeded supply, so financial resources of SOE B are mainly from revenue generated locally, and that has become in adequate to cover operating cost and maintenance as well as replacing old machines.

Another official bemoaned, "all we have are our human resource... those who went to learn must train those within, that is, trainees become trainers...

The situation for categories $\mathrm{C}$ and $\mathrm{D}$ are similar and may be summed up as woefully inadequate resources. This experience, according to the study participants from these organizations make it almost impossible for the organizations involved to effectively implements their respective PCs. It is on the basis of this that we deem resources as a vital variable in the understanding of the implementation process of PCs in Ghana. This is because the sufficiency or otherwise of financial and human resources for the implementation may correlate with the level of effectiveness of the process and therefore their variation at the organizational level could account for variations in the implementation process.

\subsection{Politics}

Another important factor that may explain why various SOEs in Ghana experience variations in their implementation efforts of PCs is politics and political interference. Politics is and has always been very influential in understanding PC implementation in Ghana. It is particularly so when it comes to those SOEs whose main line of activities target the general public. 
Politics in this context include active partisan political party activities and all other forms of conflict and reactions that are generated within the bureaucracy as well as between bureaucrats and other stakeholders in the implementation process of PCs. Political influence and politicking has been generally described as one of the main causes of unsuccessful implementation of PCs in SOEs.

The findings show that all the SOEs studied are affected significantly by politics and political interference. However, the level of interference varies across each SOE in the study. In the case of SOEs B, the political interference if seen in a form of redirecting revenue generated to other areas. Moreover, the level of interferences is in the areas of pricing, of goods and services, and non-payment of services rendered by SOEs in all four categories. In the case of those SOEs in categories $\mathrm{C}$ and $\mathrm{D}$, the interferences are mainly in the form delays in receipt of subvention from central government. Furthermore, they are coerced to undertake projects which are not economically feasible for political expediency.

\section{Concluding Remarks}

This paper sought to identify and analyse the factors that explain the mixed evidence in relation to the impact of performance contract on the performance of public enterprises. Unlike existing studies, the study drew on well-established public policy implementation models to provide more comprehensive empirical evidence. The policy implementation models take cognizance of all the processes of carrying out and translating policies into practice; and actions by public and private individuals. Furthermore, the models posits that the success or failure of any public policy depends on policy standards and objectives, policy resources, inter organizational communication and enforcement activities, characteristics of implementing agencies, economic social and political conditions, and the disposition of implementers.

Data from multiple cases randomly sampled based on performance assessment categorisation (excellent, above average, average, and fair) by the State Enterprises Commission (SEC) in Ghana, the first Anglophone nation in sub-Saharan Africa (SSA) to embark on the performance contract as part of the many reform programmes for improved public enterprise performance. Based on mainly interviews, findings of the study reveals that the content, targets, and objectives in the performance contracts are always specific, clear and measurable. There are however variations in how each of the case formulate performance targets and objectives in the contracts. SOEs in the excellent and above average categories have separate department exclusively in charge of corporate planning and that explains the variations in performance targets and objectives on yearly basis compared to those in categories C and D which show minimal changes with incremental modification to the previous targets objectives. Similarly, the study shows that SOEs in categories and A and B have clearly designed structures and systems for the implementation PC. Moreover, they were found to combine both top-down and bottom up approaches in their PC processes. Although the findings show that all SOEs face similar political inferences, financial and human resources have been identified from the study as vital in contributing to the performance of SOEs in the implementation of performance contract. 
On the basis of the above findings, this paper recommends among other things, the need for examine the institutional arrangements for formulating and implementing the content of performance contract within the SOEs. Furthermore, the approach adopted by SOE A; trainees becoming trainers must be extended to other SOEs to build competent and qualified human resource base for the SOE sector.

\section{Reference}

1. Ariyo, A, and Jerome. A, (1999). Privatization in Africa: An appraisal, World Development, Volume 27, Issue 1,Pages 201-213,

2. Basu P.K (2007). Reinventing Public Enterprises and Their Management as the Engine Of Development and Growth, In United Nations Publication, Public Enterprises: Unresolved Challenges and New Opportunities, ST/ESA/PAD/SER.E/69, United Nation. New York Pp 9-20.

3. Caulfield, J.L (2006). The Politics of Bureau Reform in Sub-Saharan Africa. Public Administration and Development, 26, pp; 15-26 (2006)

4. Chang, Ha-Joon, (2007). State-Owned Enterprise Reform, Policy Note, United Nations Department For Economic And Social Affairs (UNDESA), New York

5. Hood, C. (1995), The New Public Management In The 1990s: Variations On A Theme, Accounting Organisations And Society 20(2/3): Pp. 93-109

6. Islam, N. (1993). Public Enterprise Reform: Managerial Autonomy, Accountability and Performance Contracts. Public Administration and Development, 13:2 pp129-52.

7. Lapsley, I. (2008). The NPM Agenda: Back to the Future. Financial Accountability \& Management, 24(1), 442477-96.

8. Larbi, G. (2001). Performance Contracting in Practice: Experience and Lessons from the Water Sector in Ghana. Public Management Review, Vol. 3 Issue 3 305-324.

9. Lofland, John (1996): Analytic Ethnography: Features, Failings, and Futures. Journal of Contemporary Ethnography, 24 (1995:Apr.-1996:Jan.) p.1:30

10. Mallon, R.D. (1994). State-owned Enterprise Reform through Performance Contracts: The Bolivian Experiment. World Development, Volume 22, Issue 6, June, Pages 925-934.

11. Nellis, J. (1989). Contract Plans and Public Enterprise Performance. World Bank Discussion Paper No. 48, World Bank, Washington, DC.

12. Organisation for Economic Co-operation and Development [OECD] (1999). Performance Contracting: Lessons from Performance Contracting Case Studies. Framework for Public for Public Sector Performance Contracting, Paris: OECD.

13. Page, S., (2005), "What is new about the new public management? Administration Change in the Human Services" Public Administrative Review, November/December, VO1. 65, No. 6, pp. 713-727.

14. Rothstein, B (1998) Just Institutions Matter: The moral and political logic of universal welfare state. Cambridge University Press. 
15. Shirley, M. (2000). Why Performance Contracts for State-owned Enterprises Haven't Worked. The World Bank.

16. Shirley, M. and Xu, L.C. (1998). Information, Incentives and Commitment: An empirical Analysis of Contract between Government and State Enterprises. Journal of Law, Economics and Organizations, Vol 14, No. 2, pp;358-378.

17. Silverman, David (2004). Interpreting Qualitative Data: Methods for analysing talk, text and Interaction. 2nd ed London. Thousand Oaks. New Delhi: Sage Publications.

18. Thomas, John W. and Grindle, Merilee S. (1990) 'After the Decision: Implementing Policy Reforms in Developing Countries', World Development, Vol. 18, No.8.

19. Trivedi, P. (1990). Lack of Understanding in Memorandum of Understanding. Economic and Political Weekly, November 24.

20. Uddin S, and Tsamenyi M (2005). Public Sector Reforms and the Public Interest: A Case Study Of Accounting Control Changes And Performance Monitoring In A Ghanaian State-Owned Enterprisell. Accounting, Auditing And Accountability Journal;18(5):648-74.)

21. United Nations. (1995). Performance Contracting for Public Enterprises. United Nations, New York, U.S. Library of Congress.

22. Van Meter, D.S. Van Horn, C.E. (1975) "The Policy Implementation Process: A conceptual Framework”, Administration and Society, vol.6 No.4, February.

23. World Bank (1995). Bureaucrats in Business: The Economics and Politics of Government', World Bank Policy Research Report, Washington DC.

24. World Bank, (1983). World Development Report, Washington, DC

25. Yin, Robert K (2003). Case Study Research: Design and Methods. $3^{\text {rd }}$ Edition. Sage Publications, Inc. USA

26. Yonnedi E. (2010). Privatization, Organizational Change And Performance: Evidence From Indonesiall Journal Of Organizational Change Management, Vol. 23 No. 5, Pp. 537-563 